\title{
Evaluating the Performance of Recoverable End-of-life Products in the Reverse Supply Chain
}

\author{
Santoso Wibowo ${ }^{*}$, Srimannarayana Grandhi \\ School of Engineering \& Technology, Central Queensland University, \\ 120 Spencer Street \\ Melbourne, VIC 3000, Australia \\ E-mail: s.wibowo1@cqu.edu.au,s.grandhi@cqu.edu.au
}

\begin{abstract}
Evaluating the performance of recoverable end-of-life products with respect to a set of specific criteria is challenging. This is due to multi-dimensional nature of the decision making process, multiple evaluation criteria, and subjective and imprecise assessments. To effectively deal with this issue, this paper presents a multicriteria decision making method for evaluating the performance of recoverable end-of-life products in the reverse supply chain. The multi-dimensional nature of the performance evaluation process is handled in the context of multicriteria analysis. Linguistic terms approximated by triangular fuzzy numbers are used to tackle the subjectiveness and imprecision of the performance evaluation process. A new algorithm is developed for producing an overall performance index for every recoverable end-of-life product alternative across all performance evaluation criteria. A recoverable end-of-life products' performance evaluation problem is presented for demonstrating the applicability of the method.
\end{abstract}

Keywords: performance evaluation; recoverable end-of-life products; subjectiveness and imprecision; reverse supply chain; multicriteria

\section{Introduction}

There has been an increase in the use of natural resources for economic growth, which has resulted in an increased pressure for organizations to adopt sustainable practices by making use of recoverable end-of-life products in their production line. ${ }^{1}$ End-of-life products are products that are in their last stages of existence or in the end of its useful life. ${ }^{2}$ The use of recoverable endof-life products has become a popular option for organizations due to its ability to minimize the environmental impact of industry by (a) reusing materials, (b) reducing energy use, and (c) reducing the need to put end-of-life goods in dump yards. ${ }^{3}$
Since the introduction of green energy initiatives, several countries have adopted green practices for sustainable manufacturing and recover end-of-life products by improving their supply chain processes. ${ }^{3}$ Due to consumers green awareness, strict government and local industry regulations, organizations are compelled to adopt ways to recover end-of-life products for a safer disposal or reuse. ${ }^{4}$ For example, the Australian government enforced National Product Stewardship Scheme in 2011 to demand organizations to manage their end-of-life products. ${ }^{5}$ Therefore, in order for organizations to be competitive, there is a strong need for them to develop a strategy for

* Corresponding author. 
optimizing the reverse supply chain in order to promote efficient and effective product recovery management. ${ }^{2,6}$

Reverse supply chain processes usually involve the organizations to receive unused materials, goods and end-of-life products from their customers in reverse order. $^{7}$ This value-generating method promotes sustainable business practice by using some of the recycled parts for refurbishment and repairing goods and proper disposal of damaged parts. To ensure the successful implementation of reverse supply chain management, the process of evaluating the performance of recoverable end-of-life products and selecting the most suitable recoverable end-of-life products for product recovery are crucial for organizations. ${ }^{8}$

Evaluating the performance of the recoverable endof-life products with respect to a set of specific criteria is, however, challenging. This is due to (a) multidimensional nature of the decision making process, (b) multiple evaluation criteria, and (c) subjective and imprecise assessments. To effectively deal with this problem, an overall performance evaluation of the recoverable end-of-life products is desirable.

A few researches have been conducted for evaluating the performance of recoverable end-of-life products in organizations. ${ }^{5,7,9}$ Iakovou et al. ${ }^{5}$ apply the scoring method for end-of-life management of electronic products. The scoring method allows the decision maker to aggregate these scores with the relative importance of the evaluation criteria. As a result the overall rankings of end-of-life products can be obtained on which the selection decision can be made. Xanthopoulos and Iakovou ${ }^{7}$ apply mixed-integer linear programming method to deal with the performance evaluation of the end-of-life products in an organization. The scoring method addresses the optimization of the recovery processes, while taking into account explicitly the lead times of the disassembly and recovery processes. Kuo ${ }^{9}$ present an integrated method of case based reasoning and analytic hierarchy process (AHP) for evaluating the performance of recoverable end-oflife products. The case based reasoning is used to identify a similar problem that was overcome in the past. The AHP is then used to determine the performance of each end-of-life product with respect to each criterion and the importance of the evaluation criteria pairwisely.

These methods however are not satisfactory. They suffer from (a) the failure to adequately handle the multi-dimensional nature of the problem, (b) the inability to tackle the subjectiveness and imprecision of the performance evaluation process, and (c) cognitively very demanding on the decision maker.

To deal with those issues, this paper presents a multicriteria decision making method for evaluating the performance of recoverable end-of-life products in the reverse supply chain. The multi-dimensional nature of the performance evaluation process is handled in the context of multicriteria analysis. Linguistic terms approximated by triangular fuzzy numbers are used to tackle the subjectiveness and imprecision of the performance evaluation process. An efficient algorithm is developed for producing a performance index for every recoverable end-of-life product alternative across all the performance evaluation criteria. An example is given for demonstrating the applicability of the proposed method for evaluating the performance of recoverable end-of-life product alternatives in an organization.

\section{Performance Evaluation of Recoverable End- of-life Products}

Evaluating the performance of recoverable end-of-life products have emerged as crucial issues for organizations in fulfilling environmental responsibility while at the same time achieving profit goals within the reverse supply chain. ${ }^{2,10}$

There are various factors that affect the performance of recoverable end-of-life products in an organization. Much research has been done on identifying the critical factors for determining the performance of recoverable end-of-life products in an organization., ${ }^{4,11-20}$. Du et al. ${ }^{4}$, for example, state that technology feasibility, economic feasibility and environmental benefits are relevant factors for evaluating the performance of recoverable end-of-life products in the reverse supply chain. Dhouib and Elloumi ${ }^{11}$ believe that the performance of recoverable end-of-life products should be measured based on their impact on the environment, government regulations, cost and technology update. Bufardi et al. ${ }^{12}$ and Jun et al. ${ }^{13}$ point out that economic, social and environmental factors are critical for evaluating the performance of recoverable end-of-life products. Fernandez et al. $^{14}$ explain that the performance evaluation of recoverable end-of-life products is usually measured by the cost involved in the recovery process. 
Ziout et al. ${ }^{15}$ show that the effectiveness of recoverable end-of-life products is determined by the environmental, the societal, and the corporate intangible benefits. Chan $^{16}$ believes that economical, environmental, societal, and ecological factors play an important role in determining the performance of recoverable end-of-life products. Meanwhile, Huang et al. ${ }^{17}$ point out that the performance evaluation of recoverable end-of-life products need to take into account the social and technological factors. Berzi et al. ${ }^{18}$ state that environmental factor is the main factor to be taken into account when determining the performance of recoverable end-of-life products. Remery et al. ${ }^{19}$ point out that technological, market, and legislative concerns are key criteria for evaluating the performance of recoverable end-of-life products in the reverse supply chain. Mathieux et al. ${ }^{20}$ believe that the performance of recoverable end-of-life products should be measured on the weight recovery, the economic recoverability, and the environmental recoverability of the products. Gonzalez and Adenso-Díaz ${ }^{21}$ state that ease to disassembly and recovery revenue of the end-of-life products are two relevant factors for determining the performance of recoverable end-of-life products. Staikos and Rahimifard ${ }^{22}$ point out that the recovery cost and the recovery revenue of the recoverable end-oflife products are the two important factors for assessing the performance of recoverable end-of-life products.

A comprehensive review of the related literature shows that the performance evaluation of recoverable end-of-life products problem can be formulated as a multicriteria decision making problem. Four most important criteria are identified for evaluating the performance of recoverable end-of-life products in an organization including Technical $\left(C_{l}\right)$, Commercial $\left(C_{2}\right)$, Environmental $\left(C_{3}\right)$, and Societal $\left(C_{4}\right){ }^{2,8}$

Technical $\left(C_{l}\right)$ indicates the compatibility of parts from the end-of-life products with new equipment and its parts. ${ }^{1}$ End-of-life products consist of several parts that may or may not be compatible with the technology used in current products. Better technology compatibility in end-of-life products often suitable for reuse and recycle. ${ }^{3}$

Commercial $\left(C_{2}\right)$ reflects on the organization's effectiveness in making use of reusable materials in a market and to offer value to their customers. It is impacted by the efficiency of reusable components and refurbished products, the ability to minimize cost of manufacturing, final product performance, cost and the market demand. ${ }^{2,8}$ As demand for refurbished products is impacted by market conditions coupled with product demand and its positioning in terms of technology advancement, it is important to assess the viability prior to adopting end-of-life product components in production. $^{9}$

In the recent years, there has been significant emphasis on green logistics and environmental sustainability aspects. The green logistics predominantly aim to minimize environmental externalities. ${ }^{3}$ Environmental $\left(C_{3}\right)$ can be measured by the organization's capacity to minimize the use of resources, energy, dispersion of toxic materials, extend the shelf life and maximize the product recovery for later use. ${ }^{8}$ Undoubtedly product recovery processes consume several resources and may cause environmental externalities. However, there should be trade-offs to maintain environmental friendliness. ${ }^{5}$

Societal $\left(C_{4}\right)$ refers to the organization' knowledge about sustainable manufacturing practices such as use of components from recoverable end-of-life products and the consumers' willingness to use recovered products. The recovered products can be more appealing to consumers if these are reinvented ${ }^{7}$ and are of high quality with longer shelf-life and competitive pricing. ${ }^{2}$

To effectively evaluate the performance of recoverable end-of-life products in a given situation, it is important for the decision maker to simultaneously consider the multiple performance evaluation criteria discussed as above. To facilitate the performance evaluation of the most appropriate end-of-life product, an effective multicriteria decision making method is presented in the following section.

\section{The Multicriteria Decision Making Method}

Evaluating the performance of recoverable end-of-life products usually involves in (a) discovering all the available alternatives, (b) identifying the multiple evaluation criteria and sub-criteria, (c) assessing the performance ratings of the recoverable end-of-life products alternatives and the weights of the criteria and sub-criteria, (d) aggregating performance ratings and criteria weights for producing an overall performance index for recoverable end-of-life product alternatives. ${ }^{23}$

To better model the subjectiveness and imprecision of the decision making process, linguistic terms which 
have been found intuitively easy to use ${ }^{24}$ are used to represent the decision maker's subjective assessment. Triangular fuzzy numbers are used to represent the approximate value of linguistic terms, denoted as $\left(a_{1}, a_{2}\right.$, $a_{3}$ ), where $1<a_{1}<a_{2}<a_{3}<9$. Table I shows the linguistic terms and their corresponding triangular fuzzy numbers for the decision maker to make qualitative assessments about the performance rating of each alternative with respect to a given criterion.

Table 1. Linguistic terms used by the decision matrix

\begin{tabular}{lccccc}
\hline $\begin{array}{l}\text { Linguistic } \\
\text { terms }\end{array}$ & $\begin{array}{l}\text { Very } \\
\text { Poor } \\
(\mathrm{VP})\end{array}$ & $\begin{array}{c}\text { Poor } \\
(\mathrm{P})\end{array}$ & Fair $(\mathrm{F})$ & Good $(\mathrm{G})$ & $\begin{array}{c}\text { Very } \\
\text { Good } \\
(\mathrm{VG})\end{array}$ \\
\hline $\begin{array}{l}\text { Membership } \\
\text { function }\end{array}$ & $(1,1,3)$ & $(1,3,5)$ & $(3,5,7)$ & $(5,7,9)$ & $(7,9,9)$ \\
\hline
\end{tabular}

Table 2 shows the linguistic terms and their corresponding triangular fuzzy numbers for determining the relative importance of the criteria and sub-criteria with respect to the overall objective of the problem.

Table 2. Linguistic terms used by the weighting vectors.

\begin{tabular}{lccccc}
\hline $\begin{array}{l}\text { Linguistic } \\
\text { terms }\end{array}$ & $\begin{array}{c}\text { Very } \\
\text { Low }\end{array}$ & $\begin{array}{c}\text { Low } \\
\text { (L) }\end{array}$ & $\begin{array}{c}\text { Medium } \\
(\mathrm{M})\end{array}$ & $\operatorname{High}(\mathrm{H})$ & $\begin{array}{c}\text { Very } \\
\text { High } \\
(\mathrm{VH})\end{array}$ \\
\hline $\begin{array}{l}\text { Membership } \\
\text { function }\end{array}$ & $\begin{array}{c}(1,1, \\
3)\end{array}$ & $(1,3,5)$ & $(3,5,7)$ & $(5,7,9)$ & $(7,9,9)$ \\
\hline
\end{tabular}

The performance evaluation problem consists of a set of available recoverable end-of-life product alternatives $A_{i}(i=1,2, \ldots, n)$, to be evaluated against multiple evaluation criteria $C_{j}(j=1,2, \ldots, m)$. Each criterion $C_{j}$ may be broken down into $p_{j}$ sub-criteria $C_{j k}$ $\left(k=1,2, \ldots, p_{j}\right)$. The decision maker is required to make subjective assessments for evaluating the performance of each end-of-life product alternatives with respect to each criterion, denoted as $x_{i j}(i=1,2$, $\ldots, n, j=1,2, \ldots, m)$. As a result, the decision matrix for all the alternatives can be obtained as in (1).

$$
X=\left[\begin{array}{cccc}
x_{11} & x_{12} & \ldots & x_{1 m} \\
x_{21} & x_{22} & \ldots & x_{2 m} \\
\ldots & \ldots & \ldots & \ldots \\
x_{n 1} & x_{n 2} & \ldots & x_{n m}
\end{array}\right]
$$

If sub-criteria $C_{j k}\left(k=1,2, \ldots, p_{j}\right)$ are existent for criterion $C_{j}$, a lower-level decision matrix can be determined for all the end-of-life product alternatives, given as in (2) where $y_{i k}$ are the decision maker's assessments of the performance rating of alternative $A_{i}$ with respect to sub-criteria $C_{j k}$.

$$
Y_{C_{j}}=\left[\begin{array}{cccc}
y_{11} & y_{12} & \ldots & y_{n 1} \\
y_{12} & y_{22} & \ldots & y_{n 2} \\
\ldots & \ldots & \ldots & \ldots \\
y_{1 p_{j}} & y_{2 p_{j}} & \ldots & y_{n p_{j}}
\end{array}\right]
$$

The relative importance of the evaluation criteria $C_{j}$ and sub-criteria $C_{j k}$ respectively can be assessed qualitatively using fuzzy numbers, given as

$$
\begin{gathered}
W=\left(w_{1}, w_{2}, \ldots, w_{j}, \ldots, w_{m}\right) \\
W_{j}=\left(w_{j 1}, w_{j 2}, \ldots, w_{j k}, \ldots, w_{j p_{j}}\right)
\end{gathered}
$$

where $w_{j}$ and $w_{j k}$ are the weights of criteria $C_{j}$ and subcriteria $C_{j k}$ respectively.

The weighted fuzzy performance matrix is determined by the multiplication of decision matrix in (1) and the criteria weightings in (3) by using interval arithmetic. ${ }^{25}$ If criterion $C_{j}$ consists of sub-criteria $C_{j k}$, the decision vector $\left(x_{l j}, x_{2 j}, \ldots, x_{n j}\right)$ across all the alternatives with respect to criteria $C_{j}$ in (1) can be determined by

$$
\left(x_{1 j}, x_{2 j}, \ldots x_{n j}\right)=\frac{W_{j}, Y_{C_{j}}}{\sum_{k=1}^{P j} w_{j, k}}
$$

where $Y_{C}$ are the normalized decision matrices by

$$
y_{k i}=\frac{y_{k i}}{\sqrt{\sum_{i=1}^{n} y_{k i}^{2}}}
$$

This normalization process is required to allow a comparable scale for all performance measures, which are normally assessed by different measurement units.

Based on the fuzzy vector of the performance matrix for criterion $C_{j}$, a fuzzy maximum $\left(M_{\max }^{j}\right)$ and a fuzzy minimum $\left(M_{\min }^{j}\right)^{25}$ can be determined as in (7)-(8) which represent respectively the best and the worst fuzzy performance ratings among all the alternatives with respect to criterion $C_{j}{ }^{26,27}$ 


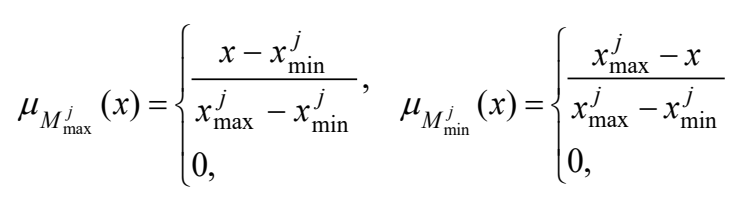

where

$$
\begin{aligned}
& x_{\max }^{j}=\sup \left(\operatorname{supp} \bigcup_{i=1}^{n}\left(w_{j} x_{i j}\right)\right), \\
& x_{\min }^{j}=\inf \left(\operatorname{supp} \bigcup_{i=1}^{n}\left(w_{j} x_{i j}\right)\right) .
\end{aligned}
$$

The degree to which alternative $A_{i}$ is the best alternative with respect to criterion $C_{j}$ can then be determined by calculating the Hamming distance between its weighted fuzzy performance $\left(w_{j} x_{i j}\right)$ with the fuzzy maximum and the fuzzy minimum ${ }^{25}$ respectively as in (10) and (11).

$$
\begin{aligned}
& h_{i}^{+}=\sum_{j=1}^{m} H\left(w_{j} x_{i j}, M_{\max }^{j}\right), \\
& h_{i}^{-}=\sum_{j=1}^{m} H\left(w_{j} x_{i j}, M_{\min }^{j}\right) .
\end{aligned}
$$

With the use of triangular fuzzy numbers, the Hamming distance between two fuzzy numbers $A=\left(a_{l}\right.$, $\left.a_{2}, a_{3}\right)$ and $B=\left(b_{1}, b_{2}, b_{3}\right)$ can be calculated as in (12).

$$
H(A, B)=\left|a_{1}-b_{1}\right|+\left|a_{2}-b_{2}\right|+\left|a_{3}-b_{3}\right|
$$

An overall performance index for alternative $A_{i}$ across all the criteria can be determined by (13). The larger the index, the more preferred the alternative.

$$
P_{i}=\frac{\left(h_{i}^{-}\right)^{2}}{\left(h_{i}^{+}\right)^{2}+\left(h_{i}^{-}\right)^{2}}
$$

The procedure for evaluating the performance of recoverable end-of-life products using the multicriteria decision making method is summarized as

Step 1. Determine the performance ratings of available alternatives.

Step 2. Determine the relative importance of the evaluation criteria and sub-criteria.

Step 3. Obtain the weighted fuzzy performance matrix by multiplying the fuzzy decision matrix (1) and the fuzzy weighting vector (3).

Step 4. Conduct normalization process to allow a comparable scale for all performance measures, given as in (6).
Step 5. Determine the fuzzy maximum and the fuzzy minimum using (7)-(9).

Step 6. Calculate the Hamming distance between its weighted fuzzy performance with the fuzzy maximum and the fuzzy minimum respectively, given as in (10)(12).

Step 7. Compute the overall performance index for each alternative by (13).

Step 8. Rank the alternatives in descending order of their performance.

\section{An Example}

To demonstrate the applicability of the proposed multicriteria decision making method above, a problem of evaluating the performance of recoverable end-of-life product alternatives is presented.

$\mathrm{ABC}$ Ltd (name to be kept anonymous) is one of the major suppliers of printers and toners in the world. As part of the company's initiative to meet the government environmental regulations and address the environmental concern of various stakeholders, the company has developed a strategy to recycle used cartridges and toner containers. About 2.5 million cartridges and toner containers are returned annually by its customers and through its recycling program, the company was able to reduce over 140 million pounds of waste in the last two decades. Based on this achievement, the company is considering of recycling multiple parts including drum units $\left(A_{l}\right)$, maintenance kits $\left(A_{2}\right)$, assembly kits $\left(A_{3}\right)$, various cartridges' materials $\left(A_{4}\right)$, assembly kits $\left(A_{5}\right)$, and fusers $\left(A_{6}\right)$.

The performance evaluation process starts with the formation of a committee involving three departmental managers. This committee has identified six recoverable end-of-life product potential alternatives, four evaluation criteria and eleven sub-criteria. The hierarchical structure of recoverable end-of-life products' performance evaluation is shown in Figure 1. Technical criteria $\left(C_{l}\right)$ concern with the subjective assessment of the decision maker on the technical feasibility of recovering the end-of-life products. This can be assessed by the technology compatibility $\left(C_{11}\right)$, the ease to disassembly $\left(C_{12}\right)$, and the condition of the end-of-life products $\left(C_{13}\right) .{ }^{8,28}$ Table 3 shows the subjective assessments. 
Level 1

Level 2

Criteria

Level 3

Sub-criteria

Level 4

Alternatives

$\mathrm{A}_{1}$

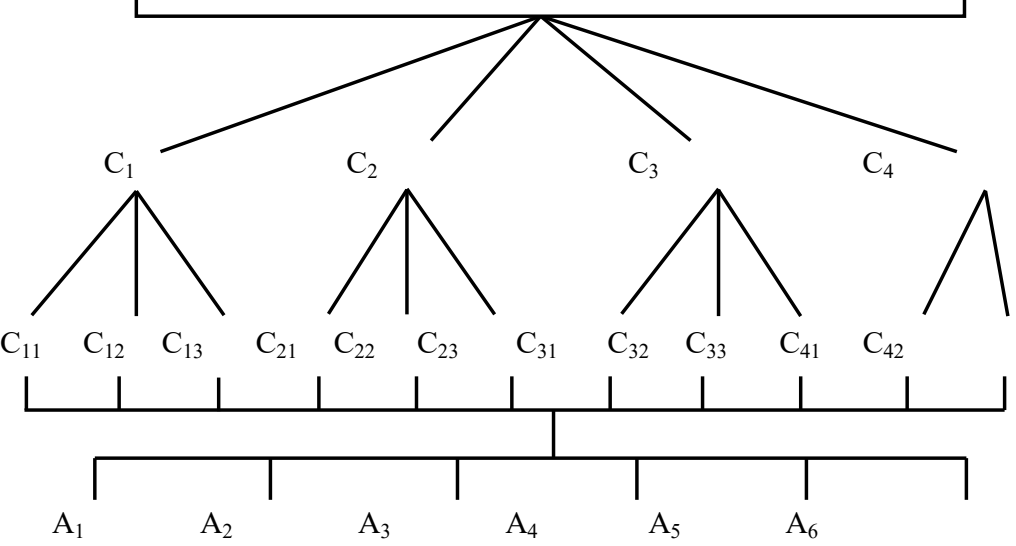

Legend:

$\mathrm{C}_{1}$ : Technical

$\mathrm{C}_{2}$ : Commercial

$\mathrm{C}_{3}$ : Environmental

$\mathrm{C}_{4}$ : Societal

$A_{i}(i=1,2, \ldots, m):$ Recoverable end-of-life products.

Fig. 1. The hierarchical structure of the recoverable end-of-life products performance evaluation problem.

Table 3. Performance assessments of alternatives for Technical $\left(C_{l}\right)$

\begin{tabular}{ccccccc}
\hline$C_{1}$ & $A_{1}$ & $A_{2}$ & $A_{3}$ & $A_{4}$ & $A_{5}$ & $A_{6}$ \\
\hline$C_{11}$ & $\mathrm{~F}$ & $\mathrm{G}$ & $\mathrm{F}$ & $\mathrm{G}$ & $\mathrm{F}$ & $\mathrm{F}$ \\
$C_{12}$ & $\mathrm{G}$ & $\mathrm{G}$ & $\mathrm{P}$ & $\mathrm{F}$ & $\mathrm{F}$ & $\mathrm{P}$ \\
$C_{13}$ & $\mathrm{G}$ & $\mathrm{P}$ & $\mathrm{F}$ & $\mathrm{G}$ & $\mathrm{F}$ & $\mathrm{P}$ \\
\hline
\end{tabular}

Commercial criteria $\left(C_{2}\right)$ refer to the subjective assessment of the decision maker on the economic benefit of recovering the end-of-life products. This can be measured by the recovery revenue $\left(C_{21}\right)$, the recovery cost $\left(C_{22}\right)$, and the return volume $\left(C_{23}\right){ }^{3,8}$ Table 4 shows the subjective assessments.

Table 4. Performance assessments of alternatives for Commercial $\left(C_{2}\right)$.

\begin{tabular}{ccccccc}
\hline$C_{2}$ & $A_{1}$ & $A_{2}$ & $A_{3}$ & $A_{4}$ & $A_{5}$ & $A_{6}$ \\
\hline$C_{21}$ & $\mathrm{P}$ & $\mathrm{G}$ & $\mathrm{P}$ & $\mathrm{F}$ & $\mathrm{F}$ & $\mathrm{F}$ \\
$C_{22}$ & $\mathrm{~F}$ & $\mathrm{~F}$ & $\mathrm{~F}$ & $\mathrm{VG}$ & $\mathrm{P}$ & $\mathrm{P}$ \\
$C_{23}$ & $\mathrm{G}$ & $\mathrm{F}$ & $\mathrm{F}$ & $\mathrm{F}$ & $\mathrm{F}$ & $\mathrm{P}$ \\
\hline
\end{tabular}

Environmental criteria $\left(C_{3}\right)$ refer to the subjective assessment of the decision maker on the positive effect of recovering the end-of-life products to environmental problems. These criteria are designed to help organizations measure their contribution to the environment and therefore to society which in turn helps to improve the organization's external image and achieve competitive advantages. This can be measured by the resources conservation $\left(C_{31}\right)$, the recovery rate $\left(C_{32}\right)$ and the pollution reduction $\left(C_{33}\right){ }^{2,5,8}$ Table 5 shows the subjective assessments.

Table 5. Performance assessments of alternatives for Environmental $\left(C_{3}\right)$

\begin{tabular}{ccccccc}
\hline$C_{1}$ & $A_{1}$ & $A_{2}$ & $A_{3}$ & $A_{4}$ & $A_{5}$ & $A_{6}$ \\
\hline$C_{31}$ & $\mathrm{P}$ & $\mathrm{F}$ & $\mathrm{F}$ & $\mathrm{G}$ & $\mathrm{G}$ & $\mathrm{F}$ \\
$C_{32}$ & $\mathrm{~F}$ & $\mathrm{G}$ & $\mathrm{F}$ & $\mathrm{F}$ & $\mathrm{G}$ & $\mathrm{G}$ \\
$C_{33}$ & $\mathrm{G}$ & $\mathrm{P}$ & $\mathrm{F}$ & $\mathrm{G}$ & $\mathrm{G}$ & $\mathrm{P}$ \\
\hline
\end{tabular}

Societal criteria $\left(C_{4}\right)$ involve the subjective assessment of the decision maker on the company's social responsibility towards its business activities. This reflects on the wider responsibilities that business has to communities in which it operates. This is assessed by the consumer opinion for green products $\left(C_{41}\right)$ and the policy encouragement $\left(C_{42}\right) .{ }^{12}$ Table 6 shows the subjective assessments.

Table 6. Performance assessments of alternatives for Societal $\left(C_{4}\right)$.

\begin{tabular}{ccccccc}
\hline$C_{1}$ & $A_{1}$ & $A_{2}$ & $A_{3}$ & $A_{4}$ & $A_{5}$ & $A_{6}$ \\
\hline$C_{41}$ & $\mathrm{~F}$ & $\mathrm{~F}$ & $\mathrm{P}$ & $\mathrm{G}$ & $\mathrm{FG}$ & $\mathrm{P}$ \\
$C_{42}$ & $\mathrm{P}$ & $\mathrm{G}$ & $\mathrm{P}$ & $\mathrm{G}$ & $\mathrm{F}$ & $\mathrm{F}$ \\
\hline
\end{tabular}

By using the linguistic terms defined in Table 2, the weights for the performance evaluation criteria and their 
associated sub-criteria can be determined. Table 7 shows the assessments results.

Based on the membership functions defined in Tables 1 and 2 for the linguistic terms used for the fuzzy decision matrix and the fuzzy weight vector, the overall fuzzy decision matrix and the overall weighted fuzzy performance matrix can then be obtained by using (5)(6). Table 8 shows the calculation results.
Table 7. Weighting vectors for the criteria and sub-criteria.

\begin{tabular}{ll}
\hline & Fuzzy criteria weights \\
\hline$W$ & $((7,9,9),(7,9,9),(5,7,9),(5,7,9))$ \\
$W_{1}$ & $((7,9,9),(5,7,9),(5,7,9))$ \\
$W_{2}$ & $((5,7,9),(7,9,9),(7,9,9))$ \\
$W_{3}$ & $((7,9,9),(5,7,9),(5,7,9))$ \\
$W_{4}$ & $((5,7,9),(7,9,9))$ \\
\hline
\end{tabular}

Table 8. The performance index of recoverable end-of-life product alternatives and their rankings.

\begin{tabular}{|c|c|c|c|c|c|c|}
\hline Criteria & $A_{l}$ & $A_{2}$ & $A_{3}$ & $A_{4}$ & $A_{5}$ & $A_{6}$ \\
\hline Technical $\left(C_{l}\right)$ & $(40.07,69.39,81)$ & $(40.07,69.39,81)$ & $(31.65,58.31,81)$ & $(35.89,63.89,81)$ & $(23.67,45.67,67.67)$ & $(21.65,44.31,63.89)$ \\
\hline $\begin{array}{l}\text { Commercial } \\
\left(C_{2}\right)\end{array}$ & $(23.23,47.23,63)$ & $(35.89,63.89,81)$ & $(31.65,58.31,74.97)$ & $(34.33,45.33,79.67)$ & $(25,47,68.33)$ & $(24.33,42.33,65.33)$ \\
\hline $\begin{array}{l}\text { Environmental } \\
\left(C_{3}\right)\end{array}$ & $(10.09,27.41,52.73)$ & $(8.55,24.55,48.55)$ & $(10.09,27.41,52.73)$ & $(23.67,45.67,67.67)$ & $(16.33,28.33,42.97)$ & $(35.67,57.67,72.97)$ \\
\hline Societal $\left(C_{4}\right)$ & $(21.65,44.31,63.89)$ & $(25,49,69.39)$ & $(28.35,53.69,74.97)$ & $(25,47,68.33)$ & $(35.67,57.67,72.97)$ & $(28.35,53.69,74.97)$ \\
\hline
\end{tabular}

Table 9. The fuzzy maximum and the fuzzy minimum.

\begin{tabular}{ccc}
\hline Criteria & $M_{\max }^{j}$ & $M_{\min }^{j}$ \\
\hline$C_{1}$ & $(31.65,81,81)$ & $(31.65,31.65,81)$ \\
$C_{2}$ & $(23.23,81,81)$ & $(23.23,23.23,81)$ \\
$C_{3}$ & $(8.55,52.73,52.73)$ & $(8.55,8.55,52.73)$ \\
$C_{4}$ & $(21.65,74.97,74.97)$ & $(21.65,21.65,74.97)$ \\
\hline
\end{tabular}

By using (7)-(9), the fuzzy maximum $\left(M_{\max }^{j}\right)$ and the fuzzy minimum ( $M_{\mathrm{min}}^{j}$ ) across all criteria can then be calculated. The results are shown in Table 9.

Based on (10)-(13), the overall performance index for each recoverable end-of-life product alternative across all the criteria and sub-criteria can be calculated in an effective and efficient manner.

Table 10. The performance index of recoverable end-of-life product alternatives and their rankings.

\begin{tabular}{lllllll}
\hline Criteria & $\mathrm{A}_{1}$ & $\mathrm{~A}_{2}$ & $\mathrm{~A}_{3}$ & $\mathrm{~A}_{4}$ & $\mathrm{~A}_{5}$ & $\mathrm{~A}_{6}$ \\
\hline Technical $\left(C_{l}\right)$ & & & & & & \\
Index & 0.635 & 0.614 & 0.558 & 0.693 & 0.582 & 0.527 \\
Ranking & 2 & 3 & 5 & 1 & 4 & 6 \\
Commercial $\left(C_{2}\right)$ & & & & & & \\
Index & 0.637 & 0.665 & 0.609 & 0.737 & 0.573 & 0.533 \\
Ranking & 3 & 2 & 4 & 1 & 5 & 6 \\
Environmental $\left(C_{3}\right)$ & & & & & \\
Index & 0.644 & 0.617 & 0.549 & 0.684 & 0.738 & 0.568 \\
Ranking & 3 & 4 & 6 & 2 & 1 & 5 \\
Societal $\left(C_{4}\right)$ & & & & & \\
Index & 0.662 & 0.718 & 0.593 & 0.731 & 0.685 & 0.627 \\
Ranking & 4 & 2 & 6 & 1 & 3 & 5 \\
Index & 0.612 & 0.655 & 0.528 & 0.729 & 0.637 & 0.574 \\
Overall ranking & 4 & 2 & 6 & 1 & 3 & 5 \\
\hline
\end{tabular}

The result in Table 10 provides the management of the company with information about the relative performance level of individual recoverable end-of-life products for all criteriaIt can be observed that the multicriteria decision making method is capable of adequately considering the multi-dimensional nature of the problem and effectively handling the subjective and imprecise nature of the performance evaluation process. The proposed multicriteria decision making method is found to be simple to use and useful for dealing with the general multicriteria performance evaluation problem involving fuzzy assessments. 


\section{Conclusion}

Evaluating the performance of recoverable end-of-life products have emerged as a crucial issue for organizations in fulfilling environmental responsibility, while at the same time achieving profit goals within the reverse supply chain.

This paper has presented a multicriteria decision making method for evaluating the performance of recoverable end-of-life products. Linguistic terms approximated by triangular fuzzy numbers are used to tackle the subjectiveness and imprecision of the performance evaluation process. An efficient algorithm is developed for producing a performance index for every recoverable end-of-life product alternative across all evaluation criteria. A recoverable end-of-life products' performance evaluation problem is presented that shows the multicriteria decision making method is simple and effective for dealing with the recoverable end-of-life products performance evaluation problem.

\section{References}

1. J. R. Huscroft, B. T. Hazen, D. J. Hall and J. B. Hanna, Task-technology fit for reverse logistics performance, Int. J. Logist. Manage. 24(2) (2013) 230-246.

2. J. Guo and G. Ya, Optimal strategies for manufacturing/remanufacturing system with the consideration of recycled products, Comput. Ind. Eng. 89 (2014) 226-234.

3. H. M. Lee, W. F. Lu and B. Song, A framework for assessing product End-Of-Life performance: Reviewing the state of the art and proposing an innovative approach using an End-of-Life Index, J. Clean. Prod. 66 (2014) 355-371.

4. Y. Du, H. Cao, F. Liu, C. Li and X. Chen, An integrated method for evaluating the remanufacturability of used machine tool, J. Clean. Prod. 20 (2012) 82-91.

5. E. Iakovou, N. Moussiopoulos, A. Xanthopoulos, C. Achillas, N. Michailidis, M. Chatzipanagioti, C. Koroneos, K. D. Bouzakis and V. Kikis, A methodological framework for end-of-life management of electronic products, Resour. Conserv. Recycl. 53 (2009) 329-339.

6. M. Sabaghi, C. Mascle and P. Baptiste, Evaluation of products at design phase for an efficient disassembly at end-of-life, J. Clean. Prod. 116 (2016) 177-186.

7. A. Xanthopoulos and E. Iakovou, On the optimal design of the disassembly and recovery processes, Waste Manage. 29 (2009) 1702-1711.

8. K. Meng, P. Lou, X. Peng and V. Prybutok, A hybrid approach for performance evaluation and optimized selection of recoverable end-of-life products in the reverse supply chain, Comput. Ind. Eng. 98 (2016) 171184.

9. T. C. Kuo, Combination of case-based reasoning and analytical hierarchy process for providing intelligent decision support for product recycling strategies, Expert Syst. Appl. 37 (2010) 5558-5563.

10. X. Sun, C. Sun, C. Quan, F. Ren, F. Tian and K. Wang, Fine-grained emotion analysis based on mixed model for product review, Int. J. Netw. Distrib. Comput. 5(1) (2017) 1-11.

11. D. Dhouib and S. Elloumi, A new multi-criteria approach dealing with dependent and heterogeneous criteria for end-of-life product strategy, Appl. Math. Comput. 218 (2011) 1668-1681.

12. A. Bufardi, D. Sakara, R. Gheorghe, D. Kiritsis and P. Xirouchakis, Multiple criteria decision aid for selecting the best product end of life scenario, Int. J. Comp. Integr. Manuf. 16 (2003) 526-534.

13. H. B. Jun, M. Cusin, D. Kiritsis and P. Xirouchakis, A multi-objective evolutionary algorithm for EOL product recovery optimization: Turbocharger case study, Int. J. Prod. Res. 45 (2007) 4573-4594.

14. I. Fernandez, J. Puente, N. Garcia and A. Gomez, A decision-making support system on a products recovery management framework. A fuzzy approach, Concurr. Eng. 16 (2008) 129-138.

15. A. Ziout, A. Azab, and M. Atwan, A holistic approach for decision on selection of end-of-life products recovery options, J. Clean. Prod. 65 (2014) 497-516.

16. J. W. K. Chan, Product end-of-life options selection: grey relational analysis approach, Int. J. Prod. Res. 46 (2008) 2889-2912.

17. H. Huang, L. Zhang, Z. Liu and J. W. Sutherland, Multicriteria decision making and uncertainty analysis for materials selection in environmentally conscious design, Int. J. Adv. Manuf. Tech. 52 (2011) 421-432.

18. L. Berzi, M. Delogu, M. Pierini and F. Romoli, Evaluation of the end-of-life performance of a hybrid scooter with the application of recyclability and recoverability assessment methods, Resour. Conserv. Recycl.108 (2016) 140-155.

19. M. Remery, C, Mascle and B. Agard, A new method for evaluating the best product end-of-life strategy during the early design phase, J. Eng. Des. 23 (2012) 419-441.

20. F. Mathieux, D. Froelich and P. Moszkowicz, ReSICLED: A new recovery-conscious design method for complex products based on a multicriteria assessment of the recoverability, J. Clean. Prod. 16 (2008) 227-298.

21. B. Gonzalez and B. Adenso-Díaz, A bill of materialsbased approach for end of-life decision making in design for the environment, Int. J. Prod. Res. 43 (2005) 20712099.

22. T. Staikos and S. Rahimifard, An end-of-life decision support tool for product recovery considerations in the footwear industry, Int. J. Comput. Integr. Manuf. 20 (2007), 602-615. 
23. S. Wibowo and H. Deng, Intelligent decision support for effectively evaluating and selecting ships under uncertainty in marine transportation, Expert Syst. Appl. 39 (2012) 6911-6920.

24. C. H. Yeh, H. Deng, S. Wibowo and Y. Xu, Fuzzy multicriteria decision support for information systems project selection, Int. J. Fuzzy Syst. 12 (2010) 170-179.

25. A. Kaufmann and M. M. Gupta, Introduction to Fuzzy Arithmetic Theory and Applications (International Thomson Computer Press, Boston, 1991.
26. S. Wibowo and H. Deng, Multi-criteria group decision making for evaluating the performance of e-waste recycling programs under uncertainty, Waste Manage. 40 (2005)127-135.

27. S. H. Chen, Ranking fuzzy numbers with maximizing set and minimizing set, Fuzzy Sets Syst. 17 (1985) 113-129.

28. J. Lee, A view of cloud computing, Int. J. Netw. Distrib. Comput. 1(1) (2013) 2-8. 